\title{
5 Research Square

\section{Satisfaction with clinical practice among nursing students using regression models and qualitative comparative analysis}

\section{David Fernández-García}

Universidad Catolica de Valencia San Vicente Martir

\section{Esther Moreno-Latorre}

Universidad Catolica de Valencia San Vicente Martir

María del Carmen Giménez-Espert ( $\square$ maria.c.gimenez@uv.es )

University of Valencia https://orcid.org/0000-0002-2095-8836

Vicente Javier Prado-Gascó

Universitat de Valencia

Research article

Keywords: clinical environment, clinical supervision, qualitative comparative models, regression models, satisfaction, sociodemographic variables

Posted Date: October 9th, 2019

DOI: https://doi.org/10.21203/rs.2.15763/v1

License: (c) (i) This work is licensed under a Creative Commons Attribution 4.0 International License.

Read Full License

Version of Record: A version of this preprint was published at Nurse Education Today on May 1st, 2021. See the published version at https://doi.org/10.1016/j.nedt.2021.104861. 


\section{Abstract}

Background: Clinical practices are considered fundamental in nursing studies for effective training of nurses and in students' satisfaction. Both the clinical environment and the clinical educator are key factors in satisfaction with the clinical practice. The aim of this study was to analyse the influence of the socio-demographic variables of clinical educators and nursing students on satisfaction with the clinical practices.

Methods: The study included 527 nursing students enrolled on the subject of clinical practice at a private university in Valencia, Spain. The age of the participants ranged from 19 to 51 years old, $(M=24.4$; $S D=6.1$ ) and 79\% (451) were women. An instrument was used to measure satisfaction with the practices based on the following scales: Clinical Learning Environment (CLE-1995), Clinical Learning Environment and Supervision (CLES-2002), Clinical Learning Environment Inventory (CLEI-2003), Clinical Learning environment, supervision and nurse teacher (CLES+T - 2008) and the Clinical Assessment Instrument (IEC-2009). Two statistical methodologies were used for data analysis: hierarchical regression models (HRM) and fuzzy-set qualitative comparative analysis model (fsQCA).

Results : The results indicate that sociodemographic variables such as sex and year group influence student satisfaction in both methodologies.

Conclusions: Based on these results, training plans to improve students' satisfaction with the clinical practice can be established.

\section{Background}

In a changing healthcare environment, with high levels of technological complexity, the users' needs are increasing. In order to guarantee the provision of high quality nursing services, it is therefore essential to study the process of teaching and learning during clinical practices of nursing students [1,2]. The students' adaptation to clinical settings plays a crucial role in the quality of education, nursing and health services [3]. Indeed, students' satisfaction with the educational process is an inherent element in quality, and analysing the students' opinions on their clinical training can provide valuable information for rebuilding and improving teaching, and for raising the level of nursing education [4]. Since clinical practice is the backbone of nursing student training, and although its importance has long been recognized [5], few studies have investigated the process of teaching and learning in clinical practice from the perspective of student satisfaction, or the competencies needed for the transition from nursing students to health professionals $[2,6,7]$. Similarly, few studies have evaluated the transfer of learning during clinical practice [8]. In addition, the few existing studies are based on analyses of linear relationships and ignore other types of relationships [5]. Accordingly, it is important for researchers, health managers and teachers to assess in depth the individual experiences and challenges that nursing students encounter in learning in the clinical setting, as they affect their well-being, academic 
performance and satisfaction [9]. Students with longer clinical practices and constant, individualized supervision are more satisfied with their clinical practice [5].

Students' participation and perceptions in the evaluation of the quality of educational programmes is now seen as a key factor [10], as improving the student's experience in their clinical learning environment can improve their learning outcomes [11], and contribute to the provision of high quality nursing care [12], Despite the importance of training new nurses, research studies on nursing education are limited [2]. In this context, it is important to highlight two elements that are fundamental in high quality clinical learning: the clinical educator [13] and the clinical environment [2]. Supervision is important for nursing students, and the literature confirms that it is essential to ensure orientation for new graduates, which contributes substantially to their job satisfaction and competence [14,15]. Meanwhile, the clinical environment is recognized as a fundamental component in learning [16] as well as the student's placement in care units facilitating the achievement of learning objectives [17]. In short, a positive relationship between the clinical educator and the student is the most important factor in determining the success of placement in the care unit [18].

For this reason, it is essential to evaluate the satisfaction of nursing students with regard to the figure of the clinical educator and the clinical environment based on their own experience [2]. In addition, it is important to consider sociodemographic variables that may influence nursing students' satisfaction with their clinical practices, age, gender, and the student's year group [19-21]. This situation will permit the design of educational programs adapted to their real needs, taking into account socio-demographic variables and using learning strategies that will enable the development of positive attitudes towards the organizational culture, encouraging commitment and quality in the nursing care provided [22,23]. We conducted an observational, cross-sectional, retrospective analytic study, to analyse the influence of the socio-demographic variables of clinical educators and nursing students on satisfaction with clinical practices. To that end, complementary methodologies, regression models and fsQCA models will be used.

\section{Methods}

\section{Participants}

The study sample consisted of 572 students on the nursing degree course at a private university in Valencia (Spain), 79\% (451) were women. The participants' ages ranged from 19 to 51 years old ( $M=$ $24.4 ; S D=6.1)$. Twenty-eight percent (158) of the students combine their studies with work. By year group, $25 \%$ (140) of the students are in the second year, $70 \%$ (402) of the students are in the third year, and $5 \%(30)$ of the students are in the fourth year.

\section{Data collection}

The inclusion criteria were students enrolled on the clinical practice course of the nursing degree who after receiving information about the study, gave their consent for participation. The anonymity and confidentiality of the information provided was indicated. The data collection process took place between 
December 2016 and September 2017. The data collection procedure consisted of the completion of an online questionnaire, which took approximately 20 minutes:

- Sociodemographic variables of the student: age, sex, in employment or otherwise, and year group.

- Sociodemographic variables of the clinical educator: age, sex, the number of services in which the clinical educator has students, and the number of students per period.

- Instrument used to measure perceived satisfaction in practices: built using scales validated in their Spanish version (Clinical Learning Environment (CLE-1995) [24], Clinical Learning Environment and Supervision (CLES-2002) [25], Clinical Learning Environment Inventory (CLEI-2003) [26], Clinical Learning environment, supervision and nurse teacher (CLES+T-2008) [27], and the Clinical Assessment Instrument (IEC-2009) [28]. These scales presented adequate psychometric properties in this study and previous research. Unlike its predecessors, the new instrument incorporates measurement of nursing students' satisfaction with regard to participation in nursing activities during their clinical practice using NIC (Nursing Interventions Classification) taxonomy [29], and the student's satisfaction with the university's organization of the clinical practice, a very important factor according to the literature [30-32]. Finally, an instrument of 43 items was been obtained, divided into 4 dimensions of satisfaction (with the clinical educator, the activities performed, the learning environment and with the university's organization) and the overall satisfaction as an average for each of these dimensions. A Likert scale with responses from 1 (totally disagree) to 5 (totally agree) was used. The instrument showed adequate psychometric properties: $\chi 2$ /df (degrees of freedom) $=1.36$; NNFI (non-normed fit index) $=.97 ; \mathrm{CFI}($ comparative fit index $)=.97 ; \mathrm{IFI}$ (incremental fit fix) $=.97$; RMSEA (root mean-square error of approximation) $=.02$ (Confidence Interval $=.018-.025)$; atotal $=.96$; aclinical educator $=.97$; a learning environment $=.94$; aactivities performed $=.93$; $\mathrm{a}$ university organization $=.92$.

\section{Data analysis}

Two methodologies were applied in the analysis of the influence of the socio-demographic variables of clinical educators and nursing students on satisfaction: hierarchical regression models (HRM) and qualitative comparative analysis (QCA). Linear regression models predict the dependent variable from several independent variables (multiple linear regression), and there is a linear relationship between the predictor variable and the predicted variable [33]. Equifinality, i.e. the possibility of obtaining different models or paths that lead to the same result $[34,35]$ is not taken into consideration. Meanwhile, QCA models are based on Boolean logic to identify a series of causal conditions associated with a result. They include equifinality and depend more on how these conditions are combined than on the individual contribution of each condition, as is the case in linear models.

QCA models identify the percentage of variance explained, or cases in which the model is adequate coverage, as well as indicators of goodness-of-fit and consistency [34,35]. They also include necessary conditions, which must always be present for a given result to occur, with a consistency (expressing the possible reliability or fit of a model) $\geq .90$ [35] and include sufficient conditions, which can lead to a result, 
although they do not always have to be present for a result to occur, with a consistency of around or above.75 [34].

Sufficiency analyses consider the solution coverage that indicates the variance explained (the number of observations that can be explained by a given combination of conditions), while solution consistency explains the model's reliability or fit. In addition, when we consider each condition, raw coverage indicates how many cases or observations can be explained by the conditions (variance explained), and this must be considered when choosing the most important condition [34].The unique coverage expresses the number of observations (variance) that can be explained by a particular combination of conditions, but not by other combinations. Within the different modalities of QCA, fuzzy sets QCA, is used for the analysis of pluricotomic variables.

Calibration values were first calculated for fsQCA and then qualitative analysis of fsQCA was performed. As the literature suggests, all the missing values were eliminated and the variables recalibrated [34]. In our case, $(0=$ woman; $1=$ man $),(0=$ student does not work; $1=$ student works $),(0=$ second year; $0.49=$ third year; 1 = fourth year) and all dimensions of satisfaction (total, clinical educator, learning environment, activities performed and the university's organization of the practice) were recoded $(0=3$; $0.49=3.1$ to $4 ; 1=4.1$ to 5 ). The variables for age of the student, clinical educator, services supervised, and students supervised by the clinical educator were recalibrated using Claude and Christopher fsQCA 2.5 program [36]. This was achieved by multiplying its constituent items to subsequently consider the three thresholds proposed [37]: $10 \%$ (low level or totally outside the set); $50 \%$ (intermediate level, neither inside nor outside the set); and 90\% (high level or totally within the set). The participants' responses to the analysis variables were coded at 0 and 1 , with 0 indicating absence and 1 indicating presence. However, with continuous variables or with survey factors composed of different items, we must consider three values in order to proceed to an automatic recalibration: the first (0) considers that an observation with this value is totally outside the set (low level of agreement/value, in our case, low satisfaction); the second (0.5) considers a midpoint, neither inside nor outside the set (intermediate level of agreement/value, intermediate level of satisfaction); and the last value (1) considers that the observation is fully within the set (high level of agreement/value, high level of satisfaction) [35].

After the coding of the data, the necessary and sufficient conditions were used to evaluate the effect of sociodemographic variables on satisfaction. Once the data matrix had been constructed, the cases were ordered according to the possible combinations of causal conditions, to construct the truth table. First, the possible logical combination of each condition value represented a row in the truth table. The truth table summarized the combinations of the causal condition values as the values associated in the result conditions. Second, the fsQCA analysis generated three possible solutions: complex, parsimonious and intermediate. The intermediate solution was the one recommended by Ragin [35]. According to Eng and Woodside [34] a model is informative in the fsQCA methodology when the consistency is above.75. IBM SPSS Statistics 24 (IBM Corporation) and fsQCA 2.5 software [36], were used to carry out HRM and fsQCA analyses respectively. 


\section{Results}

First, the main descriptors and calibration values of the variables studied are presented in Table 1.

- Please insert here table 1-

\section{Hierarchical Regression Models (HRM)}

The variables studied were analyzed using hierarchical regression models. The criteria variables were satisfaction (total, clinical educator, activities performed, learning environment and university organization of the clinical practice). The independent variables were the socio-demographic variables of the student (age, sex, have a work or not and year group) and of the clinical educator (age, sex, number of services in which the clinical educator has students and number of students per period). Two differentiated steps were carried out in the model. First, the socio-demographic variables of the students were entered, and the socio-demographic variables of the clinical educators were then entered in a second step.

-Please insert here table 2-

The socio-demographic variables of students and clinical educators considered (Table 2) accounted for $2 \%$ of satisfaction with the clinical educator $\left(\mathrm{R}^{2}\right.$ adjusted $\left.=.02, p \leq 0,05\right)$, and $1 \%$ of satisfaction with the clinical practices $\left(\mathrm{R}^{2}\right.$ adjusted $\left.=.01, p \leq 0,05\right)$.

In specific terms, in the linear regression model of satisfaction the year group sociodemographic variable for the student showed a positive and significant beta coefficient in satisfaction with the clinical educator $(\beta=.13 ; p \leq .01)$ and the number of students supervised by the clinical educator, a negative and significant beta coefficient $(\beta=-.11 ; p \leq .05)$. For the socio-demographic variables of the student, sex and year group, they showed negative and significant beta coefficients $(\beta=-.08 ; p \leq .05)$ and $(\beta=-.09 ; p \leq .05)$ respectively in the satisfaction dimension with the university's organization of the practices.

Fuzzy sets qualitative comparative analysis model (fsQCA)

Necessary analysis

According to the results obtained in table 3 , the student's year group is a necessary condition for overall satisfaction (consistency $=.91$ ) and is a necessary condition if the consistency is $\geq .90$ [35]. Students in lower year groups are more satisfied with their clinical practices.

-Please insert here table 3-

Sufficiency analysis

In sufficiency analyses, a model is informative when the consistency is above or around.75 [34]. Regarding the variance explained about satisfaction (Table 4), ten paths were observed that accounted 
for $67 \%$ of the cases with high levels of overall satisfaction (overall consistency $=.92$; overall coverage $=.67$ ). The most important path to explain high levels of overall satisfaction was the interaction of being a woman, a young person, being in the second year and not working while studying (raw coverage $=.31$; consistency $=.94$ ), which accounted for $31 \%$ of the cases with high overall satisfaction.

The high levels of satisfaction with the clinical educator, were found eighteen paths that explained $56 \%$ of the variance explained (overall consistency $=.86$; overall coverage $=.56$ ). The most important path that explains high levels of satisfaction with the clinical educator was the result of the interaction of being a woman, in the second year group, working and with a clinical educator who was also a woman, which accounted for $28 \%$ of the cases with high satisfaction with the clinical educator (raw coverage $=.28$; consistency $=.85)$.

For high levels of satisfaction with the learning environment, seven paths explained $60 \%$ of the cases (overall consistency $=.93$; overall coverage $=.60$ ). The most important path to explain high levels of satisfaction with the learning environment was the interaction of being a woman, in the second year of the course and not working while studying, which accounted for $38 \%$ of the cases (raw coverage $=.38$; consistency $=.94)$.

The high levels of satisfaction with the activities performed, were found thirteen paths clarified $55 \%$ of the variance explained (overall consistency $=.93$; overall coverage $=.55$ ). The most important path to explain high levels of satisfaction with the activities performed resulted from the combination of both the student and the clinical educator being a woman, not working while studying, and the clinical educator being young, which accounted for $25 \%$ of the cases (raw coverage $=.25$; consistency $=.92$ ).

Finally, eleven paths clarified $66 \%$ of the variance explained in the case of high levels of satisfaction with the practices (overall consistency $=.95$; overall coverage $=.66$ ). The most important path accounts for $39 \%$ of the cases (raw coverage $=.39$; consistency $=.96$ ), and was being a woman, on the second year of the course and not working while studying.

- Please insert here table 4-

\section{Discussion}

This study analysed the influence of the socio-demographic variables of the clinical educators (age, sex, number of services in which the clinical educator has students and number of students per period) and of the nursing students (age, sex, in employment or otherwise, and year group) on their satisfaction with the clinical educator, learning environment, activities performed, the university's organization of the clinical practice and overall satisfaction. Two complementary methodologies, regression models and fsQCA models, were used to do this.

In general, the regression studies suggest that the year group variable is predictive for satisfaction with the clinical educator and satisfaction with the university's organization of the practice. The number of 
students supervised by the clinical educator is also considered a predictor variable for satisfaction with the clinical educator.

According to the results obtained in the fsQCA models, the year group variable, and specifically being in lower year groups, is a necessary condition for the students' overall satisfaction with their clinical practices. For sufficiency analyses, the most important interactions in the prediction of overall satisfaction were as follows: being a woman, being young, being in the second year and not working while studying. For satisfaction with the clinical educator, they were being a woman, being a second year student, working and with a clinical educator who is also a woman. In satisfaction with the learning environment, they were being a woman, being a second year student and not working while studying. For satisfaction with the activities performed, the most important interactions were the combination of being a woman for both the student and the clinical educator, not working while studying and a young clinical educator. Finally, in the satisfaction with the organization of the practices, the main predictors were being a woman, being a second year student and not working while studying. In general, in the prediction of satisfaction, the conditions that were the best predictors were the sex of the clinical educator and student, being a woman and the year group, i.e. being in the second year. These findings could be justified given that students in higher year groups have received more knowledge and skills, and as such have greater judgement and awareness of the real difficulties in clinical practices: ethical dilemmas, the quality of patient care, unit workloads, supervising and student follow-up [19,21]. As regards the sex variable, more research is needed on these results since they are of great importance to nurses, and although there are an increasing number of men, it is still a highly feminized profession [39]. A distinguishing feature of our study is that there are no previous studies that evaluate the process of teaching and learning in clinical practice from the perspective of the students' satisfaction, using that evaluates both the nursing interventions (NIC) and the organization of the students' practices by the university. The studies that evaluate satisfaction with clinical practices are based on the analysis of linear relationships [5], ignoring other variables such as sex, working while studying, and being in higher or lower year groups, which can influence nursing students' satisfaction with their clinical practices.

The literature contains studies that suggest regular and uninterrupted access as key factors for adequate satisfaction with the clinical educator, as well as the creation of an active learning environment in which objectives are established that facilitate a professional development appropriate to the student's level of ability $[1,40,41]$. Other factors include the number of students supervised, and the empathy, kindness and trust in the clinical educator $[17,42]$.

The clinical environment and the clinical educator are key elements related to satisfaction and safety skills in patient care [43]. We found studies consistent with our findings that indicate that sociodemographic variables such as sex, being a woman, and being in second grade predict levels of satisfaction with clinical practices $[5,19,44,45]$. The results of this study reinforce the importance of the quality of clinical supervision and the quality of the clinical practice as key factors in students' satisfaction with their clinical training. These findings may be taken into consideration when developing academic plans to improve students' satisfaction with clinical practices, especially in the later years (3rd 
and 4th) and have a significant impact on nursing students and on the quality of care provided to patients. Academic plans could aim to encourage students' training using clinical simulation to improve the transition from theory to practice, increase the training of clinical educators, and the ways in which the clinical educator communicates with the academic educator [2].

\section{Limitations of the study}

Despite the importance of the information obtained for nursing students, the study has the following limitations: the sample was not probabilistic and obtaining the data only in Valencia makes it difficult to generalise the results. In the future, it could be interesting to extend the study to other populations in Spain and other Spanish-speaking countries. Another limitation is the use of self-reporting to collect the data. Although self-reports are a standard research tool, they can lead to biases due to social desirability [46]. The results should be combined with other external, objective measures.

\section{Conclusions}

Clinical practices are considered a fundamental area in the training of nursing students. The clinical environment and the clinical educator are key elements related to satisfaction. In addition, sociodemographic variables such as gender and year group influence student satisfaction. According to our results, establishing specific academic plans for students in higher years (3rd and 4th) could improve nursing students' satisfaction with their clinical training. Adequate training of students is a key factor in the provision of high quality nursing care. In general, fSQCA analyses should be used in conjunction with other linear relationship analyses, as their results are complementary.

\section{Abbreviations}

$M=$ Medium

SD = Standard Deviation

CLE $=$ Clinical Learning Environment

CLES = Clinical Learning Environment and Supervision

CLEI = Clinical Learning Environment Inventory

CLES+T = Clinical Learning environment, supervision and nurse teacher

IEC = Clinical Assessment Instrument

HRM = Hierarchical regression models

fsQCA = Fuzzy-set qualitative comparative analysis model 
$\mathrm{NIC}=$ Nursing Interventions Classification

$\chi 2 / d f=$ Degrees of freedom

NNFI = Non-Normed Fit Index

$\mathrm{CFI}=$ Comparative Fit Index

$\mathrm{IFI}=$ Incremental Fit Fix

RMSEA = Root Mean-Square Error of Approximation

$\mathrm{QCA}=$ Qualitative Comparative Analysis

\section{Declarations}

Ethics approval and consent to participate

The study was authorized by the Research Ethics Committee of the University where the study was conducted (2017-2018-032). The students gave their consent for participation. The anonymity and confidentiality of the information provided was indicated

Availability of data and materials

The datasets used and/or analysed during the current study are available from the corresponding author on reasonable request.

Competing interests

The authors declare that they have no competing interests.

\section{Funding}

This research did not receive any specific grant from funding agencies in the public, commercial, or notfor-profit sectors.

\section{Authors' contributions}

All authors have made substantial contributions to all of the following: (1) the conception and design of the study, or acquisition of data, or analysis and interpretation of data (DFG, EML, MCGE, VPG), (2) drafting the article or revising it critically for important intellectual content (DFG, EML, MCGE, VPG), (3) final approval of the version to be submitted (and any substantially modified version that involves the author's contribution to the study) (DFG, EML, MCGE, VPG);

$A N D$ to have agreed both to be personally accountable for the author's own contributions and to ensure that questions related to the accuracy or integrity of any part of the work, even ones in which the author 
was not personally involved, are appropriately investigated, resolved, and the resolution documented in the literature.

\section{Acknowledgements}

We thank to all nursing students who participated in this in this study.

\section{References}

1. Kim HR, Kwon IS. A Phenomenological Study on Oncology Adaptation Experiences of New Nurses. Asian Oncol Nurs. 2014; 14(2): 127-138. 2. Lee S, Kim J, Jung D, Kang S. Educational needs for new graduate nurses in Korea. Nurse Educ Pract. 2019; 34:167-172.

https://doi.org/10.1016/j.nepr.2018.11.021 3. Brewer C, Kovner C, Greene W, Tukov-Shuser M, Djukic M. Predictors of actual turnover in a national sample of newly licensed registered nurses employed in hospitals. J Adv Nurs. 2011;68(3):521-538. doi: 10.1111/j.1365-2648.2011.05753.x 4. Papathanasiou I, Tsaras K, Sarafis P. Views and perceptions of nursing students on their clinical learning environment: Teaching and learning. Nurse Educ Today. 2014;34(1):57-60. https://doi.org/10.1016/j.nedt.2013.02.007 5. Admi H, Moshe-Eilon Y, Sharon D, Mann M. Nursing students' stress and satisfaction in clinical practice along different stages: A cross-sectional study. Nurse Educ Today. 2018; 68:86-92.

https://doi.org/10.1016/j.nedt.2018.05.027 6. Kim S, Choi Y. Nursing competency and educational needs for clinical practice of Korean nurses. Nurse Educ Pract. 2019; 34:43-47.

https://doi.org/10.1016/j.nepr.2018.11.002 7. Rice E. Predictors of Successful Clinical Performance in Associate Degree Nursing Students. Nurse Educ. 2015;40(4):207-211. doi:

10.1097/NNE.0000000000000136 8. Steinert Y, Mann K, Anderson B, Barnett B, Centeno A, Naismith L et al. A systematic review of faculty development initiatives designed to enhance teaching effectiveness: $A$ 10-year update: BEME Guide No. 40. Med Teach. 2016;38(8):769-786.

https://doi.org/10.1080/01421590600902976 9. Van Patten R, Bartone A. The impact of mentorship, preceptors, and debriefing on the quality of program experiences. Nurse Educ Pract. 2019;35:63-68. https://doi.org/10.1016/j.nepr.2019.01.007 10. Haraldseid C, Friberg F, Aase K. Nursing students' perceptions of factors influencing their learning environment in a clinical skills laboratory: A qualitative study. Nurse Educ Today. 2015;35(9):e1-e6. doi: 10.1016/j.nedt.2015.03.015 11. Payne C. Transitions into practice: First patient care experiences of baccalaureate nursing students. Nurse Educ Pract.

2016;16(1):251-257. https://doi.org/10.1016/j.nepr.2015.09.011 12. Drew B, Motter T, Ross R, Goliat L, Sharpnack P, Govoni A et al. Care for the Caregiver. Holist Nurs Pract. 2016;30(3):148-154.

https://doi.org/10.1097/HNP.0000000000000140 13. Tsai Y, Lee-Hsieh J, Turton M, Li S, Tseng H, Lin H et al. Nurse Preceptor Training Needs Assessment: Views of Preceptors and New Graduate Nurses. J. Contin. Educ. Nurs. 2014;45(11):497-505. doi: 10.3928/00220124-20141023-01 14. Horton C, DePaoli S, Hertach M, Bower M. Enhancing the Effectiveness of Nurse Preceptors. Journal for Nurses in Staff Development. 2012;28(4):E1-E7. doi: 10.1097/NND.0b013e31825dfb90 15. Sandau K, Halm M. Effect of a Preceptor Education Workshop: Part 2. Qualitative Results of a Hospital-Wide Study. J Contin Educ 
Nurs. 2010;42(4):172-181. doi:10.3928/00220124-20101101-02 16. Liljedahl M, Boman L, Fält C, Bolander Laksov K. What students really learn: contrasting medical and nursing students' experiences of the clinical learning environment. Adv Health Sci Educ. 2014;20(3):765-779.

https://doi.org/10.1007/s10459-014-9564-y 17. O'Brien A, McNeil K, Dawson A. The student experience of clinical supervision across health disciplines - Perspectives and remedies to enhance clinical placement. Nurse Educ Pract. 2019;34:48-55. https://doi.org/10.1016/j.nepr.2018.11.006 18. Kim K, Lee A, Eudey L, Dea M. Improving Clinical Competence and Confidence of Senior Nursing Students through Clinical Preceptorship. Int J Nurs. 2014;1(2). doi: 10.15640/ijn.v1n2a14 19. Milton-Wildey K, Kenny P, Parmenter G, Hall J. Educational preparation for clinical nursing: The satisfaction of students and new graduates from two Australian universities. Nurse Educ Today. 2014;34(4):648-654.

https://doi.org/10.1016/j.nedt.2013.07.004 20. Saarikoski M, Kaila P, Lambrinou E, Pérez Cañaveras R, Tichelaar E, Tomietto $\mathrm{M}$ et al. Students' experiences of cooperation with nurse teacher during their clinical placements: An empirical study in a Western European context. Nurse Educ Pract. 2013;13(2):78-82. https://doi.org/10.1016/j.nepr.2012.07.013 21. Warne T, Johansson U, Papastavrou E, Tichelaar E, Tomietto $\mathrm{M}$, den Bossche $\mathrm{K}$ et al. An exploration of the clinical learning experience of nursing students in nine European countries. Nurse Educ Today. 2010;30(8):809-815.

https://doi.org/10.1016/j.nedt.2010.03.003 22. Allen L. On the road to a meaningful, cost-effective orientation program. Nurs Manag (Springhouse). 2011;42(5):10-12. doi:

10.1097/01.NUMA.0000396498.38628.2d 23. Green V. ENGAGE: A Different New Nurse Orientation Program. J Contin Educ Nurs. 2016;47(1):32-36. doi:10.3928/00220124-20151230-09 24. Dunn S, PhD P. The development of a clinical learning environment scale. J Adv Nurs. 1995;22(6):1166-1173.

https://doi.org/10.1111/j.1365-2648.1995.tb03119.x 25. Saarikoski M, Leino-Kilpi H. The clinical learning environment and supervision by staff nurses: developing the instrument. International Journal of Nursing Studies. 2002;39(3):259-267. https://doi.org/10.1016/S0020-7489(01)00031-1 26. Chan D. Validation of the Clinical Learning Environment Inventory. West J Nurs Res 2003;25(5):519-532. doi:

$10.1177 / 0193945903253161$ 27. Saarikoski M, Isoaho H, Warne T, Leino-Kilpi H. The nurse teacher in clinical practice: Developing the new sub-dimension to the clinical learning environment and supervision (CLES) scale. Int J Nurs Stud. 2008;45(8):1233-1237. https://doi.org/10.1016/j.ijnurstu.2007.07.00928. Navarro N. Diseño y validación de un instrumento de evaluación clínica[Design and validation of a clinical evaluation instrument]. Revista Educación en Ciencias de la Salud. 2009; 6(2):79-86. 29. Ahn Y, Choi J. Factors affecting Korean nursing student empowerment in clinical practice. Nurse Educ Today. 2015;35(12):1301-1306. https://doi.org/10.1016/j.nedt.2015.08.007 30. Kristofferzon M, Mårtensson G, Mamhidir A, Löfmark A. Nursing students' perceptions of clinical supervision: The contributions of preceptors, head preceptors and clinical lecturers. Nurse Educ Today. 2013;33(10):1252-1257. https://doi.org/10.1016/j.nedt.2012.08.017 31. Slaughter-Smith C, Helms J, Burris R. Nursing Staff Perceptions of Student Contributions in Clinical Settings. J Nurs Educ. 2011;51(1):54-57. doi:10.3928/01484834-20111130-02 32. Zhang Q, Zeng T, Chen Y, Li X. Assisting undergraduate nursing students to learn evidence-based practice through self-directed learning and workshop strategies during clinical practicum. Nurse Educ Today. 2012;32(5):570-575. https://doi.org/10.1016/j.nedt.2011.05.018 33. Hair JF, Black WC, Babin BJ, Anderson RE, Tatham RL. Multivariate data analysis 6th Edition. Pearson 
Prentice Hall. New Jersey humans: Critique and reformulation. J. Abnorm. Psychol. 2006; 87: 49-74. 34. Eng S, Woodside A. Configural analysis of the drinking man: Fuzzy-set qualitative comparative analyses. Addict Behav. 2012;37(4):541-543. https://doi.org/10.1016/j.addbeh.2011.11.034 35. Ragin C.

Redesigning social inquiry: Fuzzy sets and beyond. Wiley Online Library; 2008. 36. Claude R, Christopher R. Acq. [Computer Programme]. Houston, TX: University of Houston-Downtown.; 2014. 37. Woodside A. Moving beyond multiple regression analysis to algorithms: Calling for adoption of a paradigm shift from symmetric to asymmetric thinking in data analysis and crafting theory. J Bus Res. 2013;66(4):463-472. https://doi.org/10.1016/j.jbusres.2012.12.021 38. Fiss P. Building Better Causal Theories: A Fuzzy Set Approach to Typologies in Organization Research. Acad Manage J. 2011;54(2):393-420. doi: 10.5465/amj.2011.60263120 39. Grover S M. Shaping effective communication skills and therapeutic relationships at work: The foundation of collaboration. AAOHN Journal: Official Journal of the American Association of Occupational Health Nurses. 2005; 53(4): 177-182. 40. Chen D, Lew R, Hershman W, Orlander J. A Cross-sectional Measurement of Medical Student Empathy. J Gen Intern Med. 2007;22(10):1434-1438. https://doi.org/10.1007/s11606-007-0298-x 41. Sweet L, Broadbent J. Nursing students' perceptions of the qualities of a clinical facilitator that enhance learning. Nurse Educ Pract. 2017; 22:30-36. https://doi.org/10.1016/j.nepr.2016.11.007 42. Henning M, Shulruf B, Hawken S, Pinnock R. Changing the learning environment: the medical student voice. Clin Teach. 2011;8(2):83-87. https://doi.org/10.1111/j.1743-498X.2011.00439.x 43. Kramer M, Maguire P, Halfer D, Budin W, Hall D, Goodloe L et al. The Organizational Transformative Power of Nurse Residency Programs. Nurs Adm Q. 2012;36(2):155-168. doi: 10.1097/NAQ.0b013e318249fdaa 44. D'Souza M, Karkada S, Parahoo K, Venkatesaperumal R. Perception of and satisfaction with the clinical learning environment among nursing students. Nurse Educ Today. 2015;35(6):833-840. https://doi.org/10.1016/j.nedt.2015.02.005 45. Sundler A, Björk M, Bisholt B, Ohlsson U, Engström A, Gustafsson M. Student nurses' experiences of the clinical learning environment in relation to the organization of supervision: A questionnaire survey. Nurse Educ Today. 2014;34(4):661-666. https://doi.org/10.1016/j.nedt.2013.06.023 46. Rammstedt B, Danner D, Bosnjak M. Acquiescence response styles: A multilevel model explaining individual-level and countrylevel differences. Pers Individ Dif. 2017;107:190-194. https://doi.org/10.1016/j.paid.2016.11.038

\section{Tables}

Table 1. Main descriptions and calibration values 
Student's age Clinical educator's age Number of supervised services Number students/supervisor

\begin{tabular}{ccccc} 
M & 24.39 & 42.26 & 2.76 & 2.82 \\
SD & 6.11 & 10.27 & 3.05 & 1.65 \\
Min & 19 & 20 & 1 & 1 \\
Max & 51 & 64 & 15 & 9 \\
\multicolumn{2}{c}{ Calibration values } & & 1 \\
P10 & 20 & 27 & 1 & 3 \\
P50 & 22 & 44 & 2 & 5 \\
P90 & 35 & 56.70 & 6 & \\
\hline
\end{tabular}

Note. $\mathrm{M}=$ mean; $\mathrm{SD}=$ standard deviation; $\mathrm{Min}=$ minimum; $\mathrm{Max}=$ maximum; $\mathrm{P} 10=10$ th percentile; $\mathrm{P} 50=50$ th percentile; $\mathrm{P} 90=90$ th percentile

Table 2. Hierarchical regression analysis with the satisfaction variable.

\begin{tabular}{|c|c|c|c|c|c|c|c|c|c|c|}
\hline \multirow{2}{*}{$\begin{array}{l}\text { Variable } \\
\text { Predictors }\end{array}$} & \multicolumn{2}{|c|}{$\begin{array}{c}\text { Overall } \\
\text { Satisfaction }\end{array}$} & \multicolumn{2}{|c|}{$\begin{array}{l}\text { Clinical educator } \\
\text { satisfaction }\end{array}$} & \multicolumn{2}{|c|}{$\begin{array}{c}\text { Environment } \\
\text { satisfaction }\end{array}$} & \multicolumn{2}{|c|}{$\begin{array}{c}\text { Activity } \\
\text { satisfaction }\end{array}$} & \multicolumn{2}{|c|}{$\begin{array}{c}\text { Organization } \\
\text { satisfaction }\end{array}$} \\
\hline & $\mathrm{DR}^{2}$ & $\beta$ & $\mathrm{DR}^{2}$ & $\beta$ & $\mathrm{DR}^{2}$ & $\beta$ & $\mathrm{DR}^{2}$ & $\beta$ & $\mathrm{DR}^{2}$ & $\beta$ \\
\hline Step 1 & .02 & & .02 & & .00 & & .00 & & .02 & \\
\hline Age & & .01 & & .04 & & -.06 & & -.02 & & .03 \\
\hline Sex & & -.01 & & .02 & & -.03 & & .02 & & $.08^{*}$ \\
\hline Year group & & .04 & & $.12^{* *}$ & & -.00 & & .00 & & $-.09^{*}$ \\
\hline Working & & -.01 & & .00 & & .04 & & -.00 & & -.08 \\
\hline Step 2 & .05 & & .01 & & .01 & & .01 & & .00 & \\
\hline Age & & .00 & & .03 & & -.06 & & -.01 & & .03 \\
\hline Sex & & -.02 & & .01 & & -.03 & & .03 & & $-.08^{*}$ \\
\hline Year group & & .04 & & $.13^{* *}$ & & .01 & & .01 & & $-.09^{*}$ \\
\hline Working & & -.01 & & -.00 & & .03 & & -.01 & & -.08 \\
\hline $\begin{array}{l}\text { Age of clinical } \\
\text { educator }\end{array}$ & & -.03 & & .01 & & -.07 & & -.04 & & -.01 \\
\hline $\begin{array}{l}\text { Sex of clinical } \\
\text { educator }\end{array}$ & & .01 & & .01 & & .04 & & -.00 & & .01 \\
\hline $\begin{array}{l}\text { Supervised } \\
\text { services }\end{array}$ & & .09 & & .08 & & .10 & & .06 & & .02 \\
\hline $\begin{array}{l}\text { Supervised } \\
\text { students }\end{array}$ & & -.05 & & $-.11^{*}$ & & .00 & & .05 & & -.06 \\
\hline Total $\mathrm{R}_{\text {adjusted }}^{2}$ & -.01 & & $.02^{*}$ & & .00 & & -.00 & & $.01^{*}$ & \\
\hline
\end{tabular}

Note. ${ }^{*} \mathrm{p} \leq .05 ;{ }^{* *} \mathrm{p} \leq .01 ;{ }^{* * *} \mathrm{p} \leq .001$

Table 3. Necessity analysis for satisfaction 


\begin{tabular}{|c|c|c|c|c|c|c|c|c|}
\hline & \multicolumn{2}{|c|}{ Overall satisfaction } & \multicolumn{2}{|c|}{$\begin{array}{c}\text { Clinical } \\
\text { educator satisfaction }\end{array}$} & \multirow{2}{*}{$\begin{array}{c}\begin{array}{c}\text { Environment } \\
\text { satisfaction }\end{array} \\
\text { Cons }^{\ddagger} \\
\text { Cov }^{\S}\end{array}$} & \multicolumn{2}{|c|}{ Activity satisfaction } & \multirow{2}{*}{$\begin{array}{l}\text { Organization } \\
\text { satisfaction } \\
\text { Cons }^{\ddagger}\end{array}$} \\
\hline & Cons $^{\ddagger}$ & $\mathrm{Cov}^{\S}$ & Cons $^{\ddagger}$ & $\mathrm{Cov}^{\S}$ & & Cons $^{\ddagger}$ & $\mathrm{Cov}^{\S}$ & \\
\hline Age & .45 & .92 & .45 & .88 & $\begin{array}{l}.48 \\
.91\end{array}$ & .44 & .91 & $\begin{array}{ll}.44 & \\
& .91\end{array}$ \\
\hline Sex & .60 & .67 & .68 & .59 & $\begin{array}{l}.20 \\
.89\end{array}$ & .21 & .90 & $\begin{array}{ll}.20 & \\
& .85\end{array}$ \\
\hline Year group & .91 & .94 & .43 & .91 & $\begin{array}{l}.40 \\
.93\end{array}$ & .41 & .93 & $\begin{array}{ll}.40 & \\
& .91\end{array}$ \\
\hline Working & .27 & .89 & .28 & .86 & $\begin{array}{l}.28 \\
.91\end{array}$ & .27 & .89 & $\begin{array}{ll}.26 & \\
& .87\end{array}$ \\
\hline $\begin{array}{l}\text { Age of } \\
\text { clinical } \\
\text { educator }\end{array}$ & .50 & .93 & .49 & .87 & $\begin{array}{l}.48 \\
.92\end{array}$ & .49 & .92 & $\begin{array}{rr}.49 & \\
& .93\end{array}$ \\
\hline $\begin{array}{l}\text { Sex of } \\
\text { clinical } \\
\text { educator }\end{array}$ & .22 & .90 & .22 & .84 & $\begin{array}{l}.22 \\
.92\end{array}$ & .22 & .89 & $\begin{array}{ll}.23 & \\
& .93\end{array}$ \\
\hline $\begin{array}{l}\text { Supervised } \\
\text { services }\end{array}$ & .41 & .93 & .40 & .85 & $\begin{array}{l}.40 \\
.93\end{array}$ & .41 & .93 & $\begin{array}{ll}.40 & \\
& .93\end{array}$ \\
\hline $\begin{array}{l}\text { Supervised } \\
\text { students }\end{array}$ & .43 & .93 & .42 & .85 & $\begin{array}{l}.43 \\
.93\end{array}$ & .44 & .93 & $\begin{array}{ll}.42 & \\
& .91\end{array}$ \\
\hline
\end{tabular}

Note: ‡: consistency; §: coverage; condition needed: consistency $\geq .90$

Table 4. Summary of the three main sufficient conditions for the intermediate solution of satisfaction. 


\begin{tabular}{|c|c|c|c|c|c|c|c|c|c|c|c|c|c|c|c|}
\hline \multirow[t]{3}{*}{$\begin{array}{l}\text { Frequency } \\
\text { cut-off: } 1\end{array}$} & \multicolumn{3}{|c|}{$\begin{array}{l}\text { Overall } \\
\text { satisfaction }\end{array}$} & \multicolumn{3}{|c|}{$\begin{array}{l}\text { Clinical } \\
\text { educator } \\
\text { satisfaction }\end{array}$} & \multicolumn{3}{|c|}{ Environment satisfaction } & \multicolumn{3}{|c|}{$\begin{array}{c}\text { Activity } \\
\text { satisfaction }\end{array}$} & \multicolumn{3}{|c|}{$\begin{array}{c}\text { Organization } \\
\text { satisfaction }\end{array}$} \\
\hline & \multicolumn{3}{|c|}{$\begin{array}{l}\text { Consistency } \\
\text { cut-off: } .90\end{array}$} & \multicolumn{3}{|c|}{$\begin{array}{l}\text { Consistency } \\
\text { cut-off: } .87\end{array}$} & \multicolumn{3}{|c|}{ Consistency cut-off: .91 } & \multicolumn{3}{|c|}{$\begin{array}{l}\text { Consistency } \\
\text { cut-off: } .90\end{array}$} & \multicolumn{3}{|c|}{$\begin{array}{l}\text { Consistency } \\
\text { cut-off: } .90\end{array}$} \\
\hline & 1 & 2 & 3 & 1 & 2 & 3 & 1 & 2 & 3 & 1 & 2 & 3 & 1 & 2 & 3 \\
\hline \multicolumn{16}{|l|}{ Older } \\
\hline \multicolumn{16}{|l|}{ Man } \\
\hline \multicolumn{16}{|l|}{ Year group } \\
\hline \multicolumn{16}{|l|}{ Work } \\
\hline \multicolumn{16}{|l|}{$\begin{array}{l}\text { Age of } \\
\text { clinical } \\
\text { educator }\end{array}$} \\
\hline \multicolumn{16}{|l|}{$\begin{array}{l}\text { Sex of } \\
\text { clinical } \\
\text { educator }\end{array}$} \\
\hline \multicolumn{16}{|l|}{$\begin{array}{l}\text { Supervised } \\
\text { services }\end{array}$} \\
\hline \multicolumn{16}{|l|}{$\begin{array}{l}\text { Students } \\
\text { supervised }\end{array}$} \\
\hline $\begin{array}{l}\text { Raw } \\
\text { coverage }\end{array}$ & .31 & .25 & .22 & .28 & .24 & .22 & .38 & .25 & .15 & .25 & .21 & .20 & .39 & .33 & .27 \\
\hline $\begin{array}{l}\text { Unique } \\
\text { coverage }\end{array}$ & .05 & .04 & .02 & .06 & .03 & .02 & .07 & .06 & .03 & .09 & .01 & .01 & .04 & .01 & .03 \\
\hline Consistency & .94 & .94 & .95 & .85 & .86 & .88 & .94 & .95 & .95 & .92 & .94 & .94 & .96 & .95 & .97 \\
\hline $\begin{array}{l}\text { Overall } \\
\text { solution } \\
\text { consistency }\end{array}$ & & & .92 & & & .86 & & & .93 & & & .93 & & & .95 \\
\hline $\begin{array}{l}\text { Overall } \\
\text { solution } \\
\text { coverage }\end{array}$ & & & .67 & & & .56 & & & .60 & & & .55 & & & .66 \\
\hline
\end{tabular}

$\boldsymbol{\bullet}=$ presence of condition, $\boldsymbol{\bullet}=$ absence of condition

Expected vector for Satisfaction: 0,0,0,0,0,0,0,0 (0: absent; 1: present) using format Fiss [38]. 